\title{
Casting Technology of Aluminium Alloys in an Electromagnetic Mould for the Production of Long Workpieces of Small Diameter
}

\author{
Anton A. Avdulov $v^{\mathrm{a}, \mathrm{b}^{*}}$, Galina P. Usinina ${ }^{\mathrm{c}}$, \\ Nikolay V. Sergeev ${ }^{\mathrm{a}, \mathrm{b}}$ and Ivan S. Gudkov ${ }^{\mathrm{a}, \mathrm{b}}$ \\ a"SRC Magnetohydrodynamics" LLC \\ 9 a Kirenskogo Str., Krasnoyarsk, 660074, Russia \\ ${ }^{b}$ Siberian Federal University \\ 79 Svobodny, Krasnoyarsk, 660041, Russia \\ c " $K \& K$ " $L L C$ \\ 3 Berezina Str., Krasnoyarsk, 660020, Russia
}

Received 27.02.2017, received in revised form 17.03.2017, accepted 23.03.2017

\begin{abstract}
In this paper you see how casting speed in electromagnetic mould of aluminum alloy AMg6 effect to the structure and physical properties of the resulting workpiece diameter of $8 \mathrm{~mm}$. Metallurgical defects in microstructure are not detected such as oxides, inclusions, porosity, despite the fact that the melt does not pass the pre-cleaning, i.e. not been processed refining flux, and other degassing. The used technology enhances the uniformity of the chemical composition of the ingots. It is established that ingots of small diameters cast into an electromagnetic crystallizer have a dispersed structure with a dendritic cell size of $\sim 4 \mu \mathrm{m}$, which is characteristic for granulated aluminum alloys obtained with cooling rates of $10^{3}-10^{4}{ }^{\circ} \mathrm{C} / \mathrm{s}$. The cast material is obtained, which is equal to the deformed material.
\end{abstract}

Keywords: electromagnetic mold casting of metals in an electromagnetic field, aluminum alloys, electromagnetic influence on the melt, the high-frequency currents, granulated alloys. 


\title{
Технология литья алюминиевых сплавов
}

В электромагнитный кристаллизатор

для производства длинномерных заготовок

малого диаметра

\author{
А.А. Авдулов ${ }^{\text {,б, }}$, Г.П. Усынинав \\ Н.В. Сергеев ${ }^{\text {a, },}$, И.С. Гудков ${ }^{\mathrm{a}, \boldsymbol{\sigma}}$ \\ ${ }^{a} О О О$ «Научно-производственный цеентр \\ Магнитной гидродинамики» \\ Россия, 660074, Красноярск, ул. Киренского, 9 а \\ ${ }^{6}$ Сибирский федеральный университет \\ Россия, 660041, Красноярск, Свободный, 79 \\ ${ }^{8} \mathrm{OOO} « K u K »$ \\ Россия, 660020, Красноярск, ул. Березина, 3
}

Приведены результаты исследований структуры и свойств длинномерных слитков Ǿ 8 мм из алюминиевых сплавов, отлитых в электромагнитный кристаллизатор (ЭМК). Показано, что литье в ЭМК позволяет обеспечить чистоту металла по неметаллическим включениям без предварительной очистки расплава (рафинирования, дегазачии и т. д.). Установлено, что слитки малых диаметров, отлитые в электромагнитный кристаллизатор, имеют диспергированную структуру с размером дендритной ячейки 4 мкм, которая характерна для гранулируемых алюминиевых сплавов, полученных со скоростями охлаждения $10^{3}-10^{4}{ }^{\circ} \mathrm{C} / \mathrm{c}$. Получен литой материал, который по свойствам равен деформированному.

Ключевые слова: электромагнитный кристаллизатор, литье металлов в электромагнитном поле, алюминиевые сплавы, электромагнитное воздействие на расплав, токи высокой частоты, гранулируемые сплавы.

\section{Введение}

Развитие технологии непрерывного литья алюминиевых сплавов в электромагнитный кристаллизатор началось в 80-х гг. прошлого столетия под руководством 3.Н. Гецелева. Литье в ЭМК принципиально отличается от разновидностей литья слитков отсутствием контакта расплавленного металла со стенками формы, что повышает качество поверхности слитка [3]. Кроме бесконтактного формообразования при литье в ЭМК обеспечивается повышение интенсивности охлаждения слитков. Это происходит вследствие того, что охлаждение их осуществляется струйной подачей воды непосредственно на поверхность слитка возле фронта кристаллизации. Величина теплоотвода и, как следствие, скорость кристаллизации центральных областей лимитируются коэффициентом теплопроводности материала слитка [6]. В связи с этим в процессе литья крупногабаритных слитков возникает лункообразный фронт кристаллизации [1]. При литье слитков малого диаметра (8-12 мм) отношение площади поперечного сечения к длине 
окружности на порядок меньше, чем у крупногабаритных. Таким образом, у слитков малого сечения скорость кристаллизации будет существенно выше, особенно в центральной зоне. Благодаря этому при литье слитков малого сечения фронт кристаллизации имеет пологий вид. Важно также то, что созданные электромагнитным полем магнитогидродинамические течения в слитке малого сечения интенсивно омывают весь фронт кристаллизации [5]. Известно [2], что магнитогидродинамическое воздействие в процессе кристаллизации позволяет существенно улучшить структуру отливаемого слитка. В работах $[7,8,9,10]$ представлены результаты исследований влияния электромагнитного поля в процессе кристаллизации на структуру и свойства слитков из алюминиевых сплавов. При литье же крупногабаритных слитков в ЭМК интенсивная циркуляция расплава присутствует только на периферии слитка. В связи с тем, что структура является наиболее чувствительной характеристикой изменяющихся условий кристаллизации, в данной работе были изучены ее особенности, а также свойства слитков из алюминиевых сплавов Ǿ 8 мм, отлитых в ЭМК.

\section{Приготовление, литье сплавов и методы исследований}

В индукционной печи $\mathrm{OOO}$ «КиК» были приготовлены и отлиты в чушку алюминиевый сплав СвАМГ6, потребляемый в промышленности для производства сварочной проволоки. На опытно-промышленном плавильно-литейном комплексе с электромагнитным кристаллизатором для литья слитков малого сечения ООО «НПЦ магнитной гидродинамики» после расплавления чушки из вышеуказанных сплавов были отлиты слитки диаметром 8 мм и произведена их смотка в бухты диаметром 1300 мм. Необходимо отметить, что при приготовлении сплавов в индукционной печи, последующем расплавлении чушки и отливке слитков на плавильнолитейном комплексе с ЭМК расплав не проходил предварительную очистку, т. е. не подвергался обработке рафинирующими флюсами, дегазации и др.

Химический состав сплава СвАМГб определяли на оптическом эмиссионном спектрометpe Spectrolab-M9.

Микроструктура исследовалась с помощью оптического микроскопа «Olympus GX51». При определении размера дендритной ячейки использована система анализа изображений «SIAMS Photolab», которая работает под управлением операционных систем Microsoft Windows NT/2000/ХР. Испытания на растяжение образцов от слитков и проволоки с установлением предела прочности, предела текучести и относительного удлинения проведены на универсальной испытательной машине «WDW-20» усилием 2 т. Твердость по Бринеллю выявляли стальным шариком диаметром 5 мм при нагрузке 250 кг по ГОСТ 9012 на приборе НB-3000B.

\section{Результаты исследований и их обсуждения}

Анализ микроструктуры прутков, отлитых с разной скоростью, показал, что с повышением скорости литья возрастает теплоотвод от жидкой лунки слитка малого сечения и увеличивается скорость кристаллизации. Об этом свидетельствует дендритный параметр прутков, который уменьшается с увеличением скорости литья от 2 до 10 мм/с и составляет в среднем 8,3 и 2,2 мкм соответственно (табл. 1).

Микроструктура слитков сплава СвАМГб малого сечения Ǿ 8-10 мм, отлитых в ЭМК, характеризуется равномерным распределением по всему сечению дисперсных выделений эв- 
Таблица 1. Размер дендритной ячейки в зависимости от скорости литья прутков Ǿ 8 мм из сплава АМГ6 при литье в ЭМК

\begin{tabular}{|c|c|}
\hline Скорость литья, мм/с & Средний размер дендритной ячейки, мкм \\
\hline 2 & 8,3 \\
\hline 4 & 8,1 \\
\hline 7 & 6,7 \\
\hline 10 & 2,2 \\
\hline
\end{tabular}

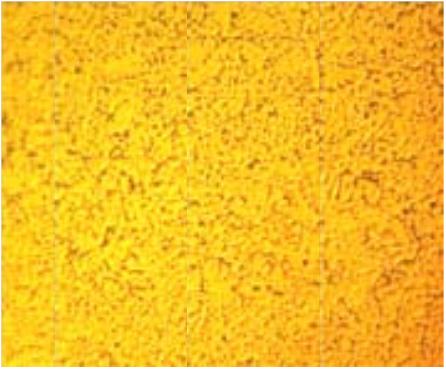

Скорость литья 2 мм/с

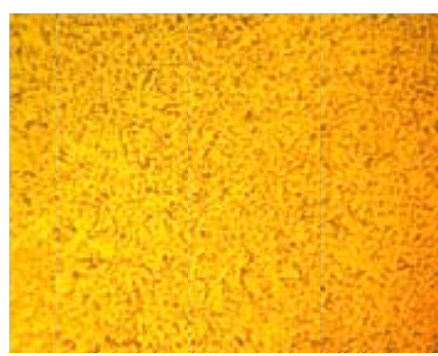

Скорость литья 7 мм/с

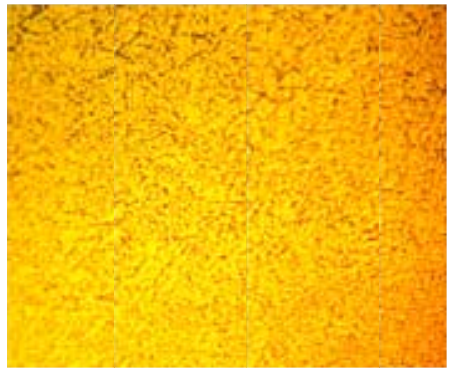

Скорость литья 4 мм/с

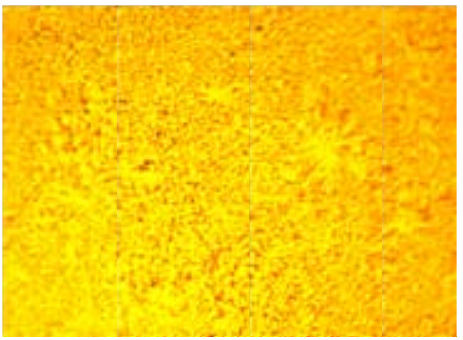

Скорость литья $10 \mathrm{mм} / \mathrm{c}$

Рис. 1. Микроструктура слитков сплава СвАМГ6 отлитых при разных скоростях. Увеличение х200

тектических фаз (рис. 1 и 2), размер которых уменьшается при увеличении скорости литья от 2 до 10 мм/с в 2 раза и составляет меньше 1 мкм. Полученная структура в литых прутках сплава СвАМГ6 с минимальной дендритной ликвацией свойственна структуре, получаемой методом гранулирования расплава и, соответственно, скоростям охлаждения $10^{3}-10^{4}{ }^{\circ} \mathrm{C} / \mathrm{c}[4]$. Этот факт также свидетельствует о значительном измельчении микроструктуры в результате высокой скорости кристаллизации расплава из-за интенсивной циркуляции расплава у зоны кристаллизации, что способствует увеличению градиента температур и, как следствие, величины теплового потока через фронт кристаллизации.

Способность к деформации, в частности к волочению, отливаемых в ЭМК прутков во многом будет зависеть от величины зерна, его равноосности и однородности по сечению. С укрупнением зерна способность литого прутка выдерживать высокие степени деформации будет уменьшаться.

Результаты определения размера зерна в исследуемых прутках показали, что оно мелкое (40-57 мкм), равноосное и однородное по сечению (рис. 3). Получением в непрерывно-литых 


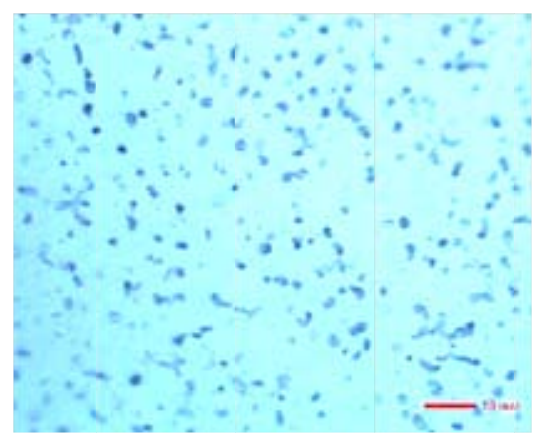

Скорость литья 2 мм/с

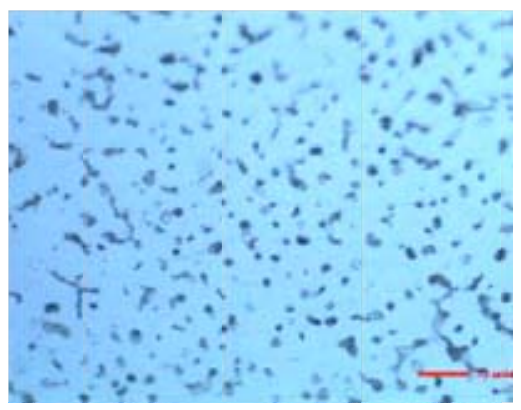

Скорость литья 7 мм/с

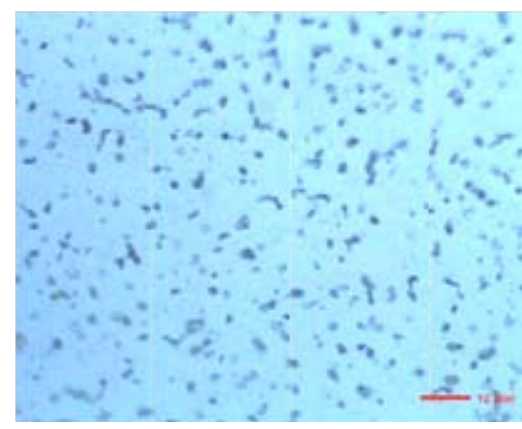

Скорость литья 4 мм/с

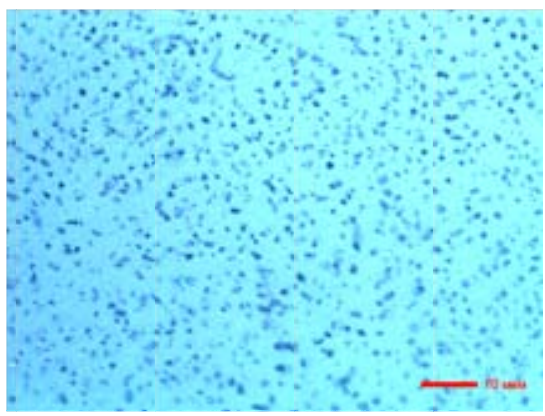

Скорость литья $10 \mathrm{mм} / \mathrm{c}$

Рис. 2. Микроструктура слитков сплава СвАМГ6, отлитых при разных скоростях. Увеличение х1000

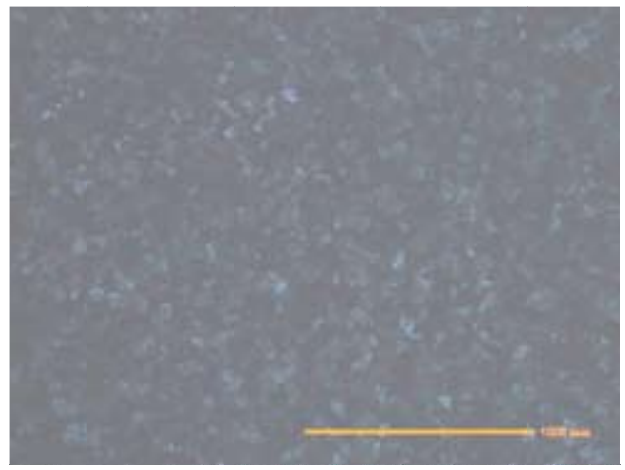

Рис. 3. Структура в поперечном разрезе слитка Ǿ 8 мм из сплава СвАМГ6

слитках малого сечения Ǿ 8 мм из сплава СвАМГ6 мелкозернистой однородной структуры с тонким внутренним строением рекомендуется проводить волочение с максимально возможными степенями деформации.

В микроструктуре непрерывно-литых слитков малого сечения Ǿ 8-10 мм из сплава СвАМГ6, отлитых в ЭМК, не обнаружены дефекты металлургического характера в виде окисных плен, твердых неметаллических включений, пористости, несмотря на то, что расплав не проходил рафинирующую обработку и отливка производилась без использования каких-либо фильтров. Отсутствие неметаллических включений и других загрязнений в слит- 
ке малого сечения, отлитом в ЭМК, связано с особенностями кристаллизации расплава в высокочастотном электромагнитном поле. Переменное электромагнитное поле, образованное индуктором кристаллизатора, наводит вихревые токи в расплаве, который непрерывно подается в область кристаллизации. Вихревые токи, взаимодействуя с магнитным полем индуктора, образуют в расплаве силы Лоренца. Данные силы равномерно обжимают расплав и обеспечивают формообразование непрерывно-литого слитка. При этом расплав не контактирует с какими-либо поверхностями. Варьируя значением электромагнитных сил в расплаве путем изменения величины и частоты тока в индукторе, можно получать непрерывно-литой слиток разного диаметра. Также электромагнитные силы образуют тороидальное течение расплава, омывающее фронт кристаллизации. В результате течения расплава примесные частицы, сталкиваясь, коагулируют в более крупные соединения. При этом окисные включения адсорбируют на своей поверхности водород. За счет разной плотности чистого расплава и неметаллических включений происходит процесс разделения сред по плотности. Включения, имеющие плотность меньше плотности расплава, флотируются на поверхность расплава. В связи с тем, что процесс литья непрерывен, при прохождении фронта кристаллизации загрязнения, находящиеся на поверхности слитка, удаляются охлаждающей жидкостью, подаваемый на слиток.

Необходимо отметить, что при литье в ЭМК крупногабаритных слитков не было зафиксировано удаление неметаллических включений. Обнаружение данного эффекта напрямую связано с диаметром слитка и интенсивностью магнитогидродинамических течений в слитке. При литье слитков малых диаметров интенсивно циркулирует весь расплав в зоне кристаллизации, а при литье крупногабаритных слитков интенсивная циркуляция расплава наблюдается только в области периферии, что не позволяет выдавить существенную долю неметаллических включений на поверхность слитка. При этом в известных электромагнитных кристаллизатоpax для литья крупногабаритных слитков специально использовались средства для снижения циркуляции расплава в области мениска слитка. При литье слитков малого сечения этого не требуется, так как диаметр струи металла, подаваемой в кристаллизатор, совпадает с диаметром отливаемого слитка.

Анализ механических свойств прутков Ǿ 8 мм сплава СвАМГ6, отлитых в ЭМК, показывает, что с увеличением скорости литья от 2 до 10 мм/с наблюдается повышение предела прочности и предела текучести на $30 \mathrm{MP}$ и на $17 \mathrm{MPa} \mathrm{соответственно} \mathrm{(табл.} \mathrm{2).} \mathrm{Зависимости}$ относительного удлинения от скорости литья слитков малого сечения в ЭМК не установлено.

Таблица 2. Механические свойства прутков Ǿ 8-10 мм сплава СвАМГб, отлитых в ЭМК

\begin{tabular}{|c|c|c|c|}
\hline \multirow{2}{*}{ Скорость литья, мм/с } & \multicolumn{3}{|c|}{ Механические свойства } \\
\cline { 2 - 4 } & $\begin{array}{c}\text { Предел прочности, } \\
\mathrm{R}_{\mathrm{m}}, \mathrm{MPa}\end{array}$ & $\begin{array}{c}\text { Предел текучести, } \\
\mathrm{R}_{\mathrm{p} 0,2}, \mathrm{MPa}\end{array}$ & $\begin{array}{c}\text { Относительное } \\
\text { удлинение, А, \% }\end{array}$ \\
\hline 2 & 335 & 164 & 20,8 \\
\hline 4 & 340 & 170 & 24,6 \\
\hline 7 & 350 & 182 & 17,0 \\
\hline 10 & 360 & 180 & 24,3 \\
\hline
\end{tabular}


Механические свойства прутков сплава СвАМГ6 в литом состоянии составили: $\mathrm{R}_{\mathrm{m}}=325-365 \mathrm{MPa}, \mathrm{R}_{\mathrm{p} 0,2}=164-181 \mathrm{MPa}, \mathrm{A}=15,8-32,3 \%$.

Такой уровень механических свойств характерен для прессованных прутков из сплава АМГ6, изготовленных из слитков, отлитых в обычный кристаллизатор.

\section{Заключение}

Литье длинномерных слитков малого сечения диаметром 8 мм, отлитых в электромагнитный кристаллизатор, обеспечивает:

- получение дисперсной структуры, сопоставимой с гранулами, за счет большего теплоотвода и интенсивной циркуляции расплава у зоны кристаллизации;

- чистоту металла по оксидным и твердым неметаллическим включениям в результате интенсивного выдавливания их на поверхность слитка электромагнитными силами, а затем удаления их охлаждающей жидкостью;

- получение в непрерывно-литых слитках такого же уровня механических свойств, как в деформированном металле.

Работа выполнена в рамках проекта «Разработка технологии производства проволоки из специальных алюминиевых сплавов для нужд авиакосмической промышленности», поддержанного Правительством Красноярского края и КГАУ «Красноярский краевой фонд поддержки научной и научно-технической деятельности» по конкурсу научно-технических проектов, направленных на кооперацию учреждений и организаций научно-образовательного комплекса Красноярского края по заказу промышленных предприятий в 2016 году.

\section{Список литературы}

1. Азаматов Р.А., Александров В.К., Андреев А.Д. и др. Металлургия легких сплавов. М.: Металлургия, 1983. с. 155-160. [Azamatov R.A. and etc. Metallurgy of light alloys. M .: Metallurgy, 1983. $155-160$ p. (in Russian)]

2. Бааке Э. МГД-технологии в металлургии. Интенсивный курс Специиализация IV. Спб.: Изд-во СПбГЭТУ «ЛЭТИ», 2013. 250 c. [А. Baake and etc. MHD technologies in metallurgy. Intensive Specialization IV. SPb.: Publishing house of the ETU “LETI", 2013. 250 p. (in Russian)]

3. Гецелев 3.Н. и др. Непрерывное литье в электромагнитный кристаллизатор. М.: Металлургия, 1983. 152 c. [Getselev S.N. and etc. Continuous casting in an electromagnetic mold. M.: Metallurgy, 1983. 152 p. (in Russian)]

4. Добаткин В.И. Гранулируемые алюминиевые сплавы / В.И. Добаткин, В.И. Елагин - М.: Металлургия, 1983. 176 c. [Dobatkin V.I., Elagin V.I. Granulated aluminum alloys. M.: Metallurgy, 1983. 176 p. (in Russian)].

5. Первухин М.В. Электротехнология и оборудование для получения непрерывнолитых слитков в электромагнитном кристаллизаторе. Теория и практика: автореф. дис. ... д. т. наук: 05.09.10. Красноярск, 2012. 36 c. [Pervukhin M.V. Electrotechnology and equipment for continuous casting ingot in an electromagnetic mold. Theory and Practice: Abstract. Dis. ... Doctor of Sciences:.. 05.09.10. Krasnoyarsk, 2012. 36 p. (in Russian)] 
6. Стеценко В.Ю. Механизмы процесса кристаллизации металлов и сплавов. Минск.: Литье и Металлургия. БНТУ 2013. 1. С. 48-54. [Stetsenko V.Y. The mechanisms of the process of solidification of metals and alloys. Minsk. Casting and Metallurgy. Belarusian National Technical University 2013. 1. P. 48-54 (in Russian)]

7. Evans J. The use of electromagnetic casting for AI alloys and other metals. JOM 471995. P. $38-41$.

8. Hai H., Xingguo Zhang, Shan Yao Improvement of Casting Speed and Billet Quality of Direct Chill Cast Aluminum Wrought Alloy with Combination of Slit Mold and Electromagnetic Coil. / Hai Hao. Materials Transactions, The Japan Institute of Metals 200. Vol. 48. P. 2194-2201.

9. Masahiro T., Masafumi Zeze, Takehiko Toh, Keiji Tsunenari Electromagnetic Casting Technique for Slab Casting. Nippon Steel Technical Report. 104, 2013.

10. Yu-bo Z., Jian-Zhong Cui, Dan Mou, Qing-feng Zhu, Xiang-jie Wang, Lei Li. Effect of electromagnetic field on microstructure and macrosegregation of flat ingot of 2524 aluminium alloy. Yu-bo Zuo. Transactions of Nonferrous Metals Society of China 2014. Vol. 2. P. 132-134. 